\title{
ENTREVISTA
}

\section{Entrevista com Peter Trawny}

Soraya Guimarães Hoepfner

soraya.hoepfner@gmail.com

(Doutora em filosofia pela Universidade Federal do Rio Grande do Norte,

Rio Grande do Norte, Brasil)

Entre fevereiro e março de 2013, vieram finalmente a público os primeiros três volumes dos Cadernos $\operatorname{Pretos}^{1}$ de Martin Heidegger, uma espécie de "registro em primeira pessoa" dos primeiros dez anos de considerações filosóficas do pensador. A entrevista a seguir, feita com o editor dos volumes, o filósofo Peter Trawny, diretor do Instituto Martin Heidegger em Wuppertal, Alemanha, foi realizada com base na leitura do primeiro volume, 94, ainda antes do lançamento oficial. Nesta conversa, o editor compartilha conosco alguns dos seus insights sobre o homem e o pensador com quem temos contato nos Cadernos, nos fala sobre o seu recém-lançado livro $^{2}$, e expõe o ponto de vista privilegiado de quem já teve acesso ao conjunto de escritos que só agora começamos a conhecer. Entre os pontos importantes desta conversa estão a sua defesa de uma releitura completa da obra de Heidegger pós Ser e Tempo. Sobretudo, Trawny nos apresenta seu argumento, que divide opiniões na comunidade acadêmica internacional, sobre em que de fato consiste o cerne do projeto filosófico de Heidegger à luz da leitura dos Cadernos Pretos.

Soraya: Prof. Trawny, começo abordando questões fatuais. Quanto tempo levou, de fato, o processo de edição dos Cadernos?

Trawny: Esses cadernos foram especialmente fáceis, pois a família [de Heidegger] já havia feito uma primeira transcrição; claro que eu me baseei no original. Assim, acho que a edição dos três volumes levou

1. HEIDEGGER, M. Überlegungen II-VI (Scbwarze Hefte 1931-1938) Band. 94; Überlegungen VII-XI (Scbwarze Hefte 1938-1939) Band. 95; Überlegungen XII-XV (Scbwarze Hefte 1939-1941) Band. 96. Ed. Peter Trawny. Frankfurt: V. Klostermann, 2014.

2. TRAWNY, P. Heidegger e o mito da conjuração judaica mundial. Trad. Soraya Guimarães Hoepfner. Rio de Janeiro: Mauad X. No Prelo. 
cerca de um ano; os próximos volumes deverão sair no outono [europeu]. São manuscritos terríveis do Heidegger, mas, em verdade, divertidos de se trabalhar.

Soraya: A primeira coisa que realmente chama a atenção é a perfeita organização lógica das notas, por exemplo, somente no Caderno III encontram-se as considerações mais políticas, mais polêmicas. Enquanto editor, você organizou as notas de algum modo, cronológico ou lógico, diferente do original?

Trawny: Não. Esta é a ordem original, nada foi modificado por mim, é um manuscrito perfeito.

Soraya: Isto é curioso e importante saber, pois quer dizer que as notas não são, de modo algum, rascunbos - o que aliás você menciona em seu epílogo, elas foram meticulosamente "trabalhadas", não foram escritas de rompante...

Trawny: Não são. Na verdade, os Cadernos não são cadernos de notas (risos). Devem ter existido anotações criadas para os Cadernos, mas elas foram provavelmente destruídas.

Soraya: E o Número I? Foi destruído? Não deveria vir a público?

Trawny: Isso é o pior... Na minha opinião, o Número I nunca existiu. Talvez tenha existido em algum momento, mas Heidegger pode tê-lo destruído. Ele sempre se referiu aos Cadernos por números, sem jamais ter mencionando um Caderno I, então eu interpretaria dessa forma: se é que algum dia existiu, não existe mais.

Soraya: Você acha possível que Heidegger tenba de fato desejado iniciar com o II, digo, numa alusão cifrada ao "segundo começo"? É claro que isso é uma curiosidade estilo fait divers, mas eu não poderia deixar de compartilhar essa ideia...

Trawny: Não sei... Eu teria que pensar sobre isso.

Soraya: Digo, não é estranbo que em algo tão detalbadamente organizado e, como você mesmo já comentou, diferente dos outros aos quais ele se refere ao longo dos anos, o Caderno I não é jamais mencionado...

Trawny: É possível, mas eu realmente teria que pensar...

Soraya: Bom, acho que esses são fatos mais relevantes para qualduer interpretação

3. HEIDEGGER, M. Überlegungen II-VI (Schwarze Hefte 1931-1938), p. 534. 
possível, então eu gostaria de passar ao questionamento filosófico, começando com a questão do significado de "ser alemão" e desse Dasein alemão que, aliás, não é necessariamente inédito, ao contrário, extensamente discutido no Volume. 38 [das Obras Completas $]^{4}$; assim como também quase 30 anos depois, quando o vemos mencionar um certo Dasein grego $0^{5} \ldots$

Trawny: Esse é um tema crucial nos anos 30 e até 1941, e não somente nos Cadernos. De fato, é verdade que, em nenhum outro manuscrito, a questão de ser alemão é tão forte quanto nessas notas. Ela é crucial para a sua narrativa filosófica sobre o primeiro e o segundo começo ${ }^{6}$, como você sabe. Está bastante claro que Heidegger conecta a Revolução Nacional-Socialista (1933/34) com o chamado "segundo começo".

Soraya: Sim, mas então justamente isso torna a compreensão lógica ainda mais difícil. Podemos sem maiores complicações nos referir a uma "filosofia grega", essa do "primeiro começo", e isso pode inferir os gregos enquanto povo, assim como também a lingua grega. Nesse sentido, também a filosofia alemã é unica, aqui eu me refiro, é claro, a todos que antecederam Heidegger, mesmo que ele próprio nesse Caderno chegue ao ponto de citar tão somente a sua data de nascimento, juntamente com as datas de nascimento e morte de Wagner e Nietzsche como os "grandes eventos" da bistória alemã $\tilde{T}^{7}$ Veja bem, não estou aqui elaborando nenbuma desculpa para justificar a desmesura do orgulbo beideggeriano, ou alemão, apenas sugerindo que faz certo sentido - dentro da lógica beideggeriana - pensar a particularidade do alemão para a bistória do pensamento ocidental. Porém, se por um lado bá lógica nessa relação e, por conseguinte, épossível inferir a importância de uma filosofia para uma revolução,

4. HEIDEGGER, M. Logik als die Frage nach dem Wesen der Sprache. Ed. Günter Seubold. Frankfurt: Klostermann, 1998.

5. Auftenhalt: Séjours. (Édition Bilingue) Ed. François Vezin. Paris: Editions du Rocher, 1992.

6. Heidegger se refere sistematicamente aos alemães como portadores da tarefa de retomada da primeira disposição fundamental dos gregos para com a questão de Ser. Na essência de ser alemão residira, portanto, essa condição de possibilidade, de se mostrar desprovido de coragem "atolmos para essa retomada, ao mesmo tempo em que desse questionar advém a coragem 'tolma' para um outro começo". (HEIDEGGER, M. Überlegungen II-VI (Scbwarze Hefte 1931-1938), p. 96). Essa ideia reaparece frequentemente como "outro começo" [Der anderen Anfang] ou um "recomeçar" [das Wiederanfangen] em diversas passagens.

7. HEIDEGGER, M. Überlegungen II-VI (Schwarze Hefte 1931-1938), p.523. 
para que Heidegger precisaria então do povo? Qual é o papel do povo nisso tudo?

Trawny: É claro que a compreensão que Heidegger tem dos alemães é esquisita. E não é a língua alemã, mas é precisamente Hölderlin e Nietzsche. Eles são os grandes representantes do que significa ser alemão. Claro que Hölderlin mais do que Nietzsche, mas em todo caso, nos anos 30, Nietzsche ainda é uma figura muito forte. Isso é esquisito, porque poderíamos dizer que Hölderlin é um poeta muito importante, e que Nietzsche é um pensador muito importante, mas você não pode fazer política com isso. Você não pode dizer, "eu tenho um projeto metapolítico e vou conectá-lo à poesia de Hölderlin!". Isso é muito estranho, nenhum alemão das ruas, uma pessoa comum, estava interessado em Hölderlin ou Nietzsche; então isso é esquisito desde o começo. O mais alemão entre os alemães é Hölderlin, e esse é o sentido epocal do povo alemão....(!) Nessa estranha relação, o principal predicado do ser alemão é atribuído a Hölderlin, e isso é problemático desde o começo, porque é óbvio que não se pode discutir Hölderlin com os nazistas. Em todo caso, Hölderlin é uma fonte principal nessa narrativa e é como Heidegger estabelece uma conexão com os alemães, da maneira mais curiosa. Mas, sim, caso Heidegger tenha tido um sujeito político, ele é o povo. Esse povo, entretanto, não é o produto da cultura, que ele recusa e critica como conceito. O povo é um conceito político, um conceito principal.

Soraya: Então, mesmo para você, não parece claro porque ele "precisa" do povo nesse contexto, a não ser que façamos um exercício entre níveis ôntico e ontológico...

Trawny: De certo modo, ele sempre pensou que a filosofia só poderia ser possível na esfera de um povo. Eu diria que, para ele, filosofia deve ser sempre alemã ou grega; não há algo como filosofia em si, mas sim, há sempre uma filosofia no contexto de um povo. Não é jamais universal, sem conexão com um certo topos, um lugar. E lugar nesse ponto está sempre conectado a Terra, que está, por sua vez, sempre conectada com o povo...

Soraya: Na pág. 233 do volume 94 dos Cadernos ${ }^{8}$, após listar uma série de dez caracteres negativos do seu tempo presente, marcado por uma "visão de mundo" [Weltanschaunng] e "falta de princípios" [Prinzip-losigkeit] da filosofia, Heidegger encerra dizendo: "Tudo isso é, em princípio, não-alemão - O que pode um pensador

8. HEIDEGGER, M. Überlegungen II-VI (Scbwarze Hefte 1931-1938). 
em tempos ruidosos?" 9 . A partir dessa nota, eu gostaria de considerar por um momento a bipótese de que a filosofia pertence, a cada vez, ao seu presente. Ao filosofarmos, o fazemos invariavelmente a partir do nosso modo atual de ser, a partir do nosso tempo presente. Daí porque, aliás, todo exercício de "olbar para trás" e buscar um diálogo com Heidegger e seu tempo já se mostra como uma certa impossibilidade. Mas, o que eu gostaria de dizer com isso é que a filosofia diz respeito a um instante - que existe em conexão com um determinado presente. Caso você aceite essa bipótese, poderíamos então dizer que Heidegger demandava para sua filosofia uma certa circunstância de presente, necessária para instigar um determinado instante filosófico, para ele ideal? Heidegger mostra-se terrivel e incrivel ao mesmo tempo porque responde como tal ao seu tempo? Também veja que nessa pergunta reside a premissa de que a filosofia não é um mero produto de uma mente pensante, não é uma "visão de mundo", mas uma co-respondência ao mundo, ao que é. Isso lhe parece plausível? Quereria Heidegger forjar um determinado presente que correspondesse a um instante filosófico ideal?

Trawny: Há um certo tempo filosófico que é típico, mas eu diria que para Heidegger o tempo necessário é o da revolução. Isto quer dizer que ele não está tratando do mundo de uma determinada comunidade, mas sim de historicidade [Gescbicbtlicbkeit]. E história é para ele somente uma situação de irrupção, de ruptura de algo que termina e começa. Então o ponto central aqui é revolução. Primeiro, ele tem um ponto de vista até positivo sobre a Revolução do Nacional-Socialismo, mas depois, ele se torna mais crítico a respeito. Em todo caso, a revolução do Nacional-Socialismo foi para ele um indício, um sinal, um traço de uma determinada situação histórica, e essa situação histórica demandava uma resposta, como você diz. Nesse sentido, o NacionalSocialismo foi, então, uma provocação real para pensar essa situação. Mais tarde, ele vai dizer que o problema é que ele entendeu o outro começo, mas o Nacional-Socialismo não. Então você poderia dizer que, nessa fase, ele está pensando esse segundo começo. Nas aulas do semestre de verão de 1932, intituladas Parmênides ${ }^{10}$, você vê um filósofo lidando com os gregos, e com uma excelente ideia sobre um segundo começo. Mas então, inesperadamente algo acontece: a revolução. Ele provavelmente pensou que deveria haver uma conexão, que não se tratava de uma mera coincidência; e então ele apresenta (ou tenta) uma filosofia para essa revolução, porque ele pensava que esta

9. Idem, p.233.

10. Heidegger. M. Der Anfang der abendländische Pbilosopbie. Auslegung des Anaximander und Parmenides. Band 35. Ed. Peter Trawny. Franfkurt: V. Klostermann, 2012. 
revolução (e isso é loucura) poderia ser um segundo começo. Eu, no entanto, diria que não me parece muito sensato ver Hitler como uma resposta aos gregos, mas provavelmente Heidegger chegou a pensar que poderia ser.

Soraya: Mas como épossivel que ele tenba depositado em um movimento político essa carga filosófica?

Trawny: Não foi uma revolução normal, não foi democrática em nenhum sentido, foi iniciada por um gênio político, o qual ele chama de "pai do estado". Heidegger estava fascinado por Hitler porque esse não era um homem comum, Hitler conhecia Nietzsche, Wagner, era muito mais um arquiteto do que um político. De certo modo, Hitler desprezava a política, e isto foi algo interessante para Heidegger, ver um político que despreza a política, a administração, que de certo modo tenta fazer política como arte. Isso talvez tenha representado para ele a possibilidade de conectar seu pensamento a este projeto (político).

Soraya: Esse momento de delírio foi, no entanto, relativamente curto; essa esperança não dura muito. Então, como esse momento pode responder por toda a obra de um bomem?

Trawny: A obra de um homem como Heidegger? Se você considerar Ser e Tempo ${ }^{11}$, esta foi, claro, a coisa mais importante que ele fez. E ele vai para sempre se referir a ela. Mas, o que acontece depois de Ser e Tempo? Eu acredito que temos que revisitar o período pós- Ser e Tempo de uma nova maneira. Entre 1928 e 1930, ele na verdade não sabia o que fazer. Ele fez uma coisa aqui, outra ali, mas não realizou muita coisa, ele procurava algo, era um filósofo sem uma ideia...

Soraya: Ou um filósofo com uma ideia obsessiva, o sentido de Ser...?

Trawny: Ou um como uma ideia obsessiva, mas ele estava, de certo modo, incomodado. As aulas são interessantes, mas não tão importantes quanto Ser e Tempo, elas não têm um contexto claro. Veja, por exemplo, o conceito de meta-ontologia: muitos estudiosos heideggerianos estão lidando com talvez 25 páginas de um curso, mas Heidegger nunca

11. HEIDEGGER, M. Ser e Tempo. Tradução de Marcia C. S. Shuback. Rio de Janeiro: Vozes, 2006. 
mais volta a esse assunto...

Soraya: Você está se referindo aos Fundamentos Metafísicos da Lógica ${ }^{12}$ ?

Trawny: Exatamente. Isto talvez tenha sido tematizado durante semanas, um ano, mas não era a ideia para ele. A ideia para Heidegger, e eu estou bastante certo disso, é a relação entre o primeiro e o segundo começo; entre os gregos e os alemães, e ele vai tentar executar essa ideia nos anos 1930 e 1940 com todas as suas forças. Então, entre 1944-45, quando se torna cada vez mais claro que ele fracassa, que esse projeto não vai acontecer, ele entra em colapso; não somente seu pensamento colapsa, mas ele mesmo tem um colapso nervoso. Ele sofreu com o fracasso desse projeto. E ele tem que desenvolver novas estratégias; você pode ver claramente, nos cadernos de 1946-47, que ele busca um novo ponto de partida. Porque ele sabia que não poderia continuar com esse projeto, era o fim. Infelizmente, muito infelizmente, essa narrativa dos gregos e alemães era seu autêntico e genuíno projeto. Veja que mesmo na entrevista para a Der Spiegel ${ }^{13}$ ele fala sobre a importância histórica dos alemães e gregos, isso em 1966! Ele nunca abandonou esse projeto, mas estava claro que ele sabia que não era muito conveniente falar disso em público.

Soraya: Que pena, en particularmente tinha a romântica ideia de que todo o tempo, de fato, ele exercitava a manutenção da questão pelo sentido de Ser, que essa era "a questão", que, aliás, aparece repetidamente em todas as partes desse primeiro volume dos Cadernos, como aquilo digno de ser questionado. Ou seja, ao longo dos anos, sua filosofia tratou dessa pergunta, sempre a cada vez, de acordo com cada tempo de mundo, seja o tempo da técnica, da cibernética e, por último, da informação. Eu pensava que a filosofia de Heidegger tratava de refletir renovadamente o modo de aparição/ocultação de Ser...

Trawny: Antes de mais nada, quero dizer que essa é a minha interpretação, algo que eu tento explicar em meu livro. Essa narrativa é, de fato, no que realmente consiste seu projeto filosófico. É apenas uma interpretação, não quero lutar por ela, isso não é o que me

12. HEIDEGGER, M. Metapbysische Anfangsgründe der Logik im Ausgang von Leibniz. Band 26. Ed. Klaus Held. Frankfurt: V. Klostermann, 1978.

13. HEIDEGGER, M. Das Spiegel Gespräch (1966). In: Aus der Erfabrung des Denkens (1910-1976). Band 13. Ed. Friedrich-Wilhelm von Herrmann. Frankfurt: V. Klostermann, 2002. 
interessa, e eu queria poder estar enganado, mas não acho que seja o caso. Se você tomar, por exemplo, o problema da técnica, que particularmente lhe interessa, nos anos 30, você não acha que ele é totalmente contra ela?

Soraya: Bem, ao ler esse volume, vejo um bomem raivoso, mas também amedrontado; alguém que não está nada satisfeito com o curso das mudanças no mundo, da transformação do mundo em cultura, organização, em visão de mundo... Mas, isto éprecisamente o que torna a compreensão mais difícil e a situação ainda mais estranba, pois, se partimos do ponto de vista da visão que Heidegger tem da técnica nessa época $e$, por outro lado, observarmos o Nacional-Socialismo, algo não bate, pois não é justamente o Nacional-Socialismo a personificação da técnica por excelência, o que poderia baver de mais técnico?

Trawny: Sim, é...

Soraya: Então, isso parece inconsistente para mim...

Trawny: E assim ele critica o Nacional-Socialismo. Você deve ver que há uma diferença entre os alemães e os nacional-socialistas; e esta é uma diferença ainda mais esquisita. Está bastante claro que os alemães não são os nacional-socialistas; esses são inegavelmente os representantes da tecnologia, assim como, aliás, os judeus serão mais tarde esses representantes.

Soraya: Porfalar nisso, corrija-me se eu estiver enganada ou não li o Vol. 94 direito, mas nele não bá nenbuma menção aos judeus, estou certa?

Trawny: Não, não há. Isso vai aparecer no próximo volume [Vol. 95]. Mas, então, você mesma falou em esperança: Heidegger tinha a esperança de que as promessas antimodernistas dos nazistas fossem cumpridas. Porém, claro que os nazistas estavam apenas interessados em dominar o mundo; a única coisa que queriam era tecnificar o mundo. Mas, isso Heidegger só vai reconhecer em 1934-35, e então ele se torna, obviamente muito revoltado com os nazistas. Quando ele fala de maquinação [Machenshaft $]^{14}$ nessa época, ele não é capaz de encontrar o ponto de vista. Nos anos 50, como você já mencionou, ele está livre

14. No Caderno III, Heidegger critica a ascensão de um "Nacional-socialismo vulgar" e da historicidade velada em cada maquinação. Cf.: HEIDEGGER, M. Überlegungen II-VI (Scbwarze Hefte 1931-1938), p. 142. 
o bastante para dizer que o enquadramento [Gestell] é nosso mundo, e que não podemos ter um ponto de vista fora dele. Ele está realmente irado, agressivo, lutando contra a tecnologia, porque pensa que a tecnologia é niilista, que ela é algo undeutsch [não alemão]. De certo modo, isso é muito problemático. Nem preciso dizer que é absurdo em termos filosóficos.

Soraya: Também é problemático porque, todo o tempo, ele está tentando justamente afirmar que sua perspectiva, antes de mais nada, não é uma mera crítica da modernidade, mas uma filosofia pura lidando com o mundo, e o mundo não é algo que alguém possa lutar contra. Mas, no entanto, do mesmo modo que, também para ele, os gregos tiveram o seu momento de "pisar em falso", de ter uma "falsa" perspectiva de relação com as coisas, isso não quer dizer que o primeiro começo foi ao mesmo tempo um primeiro contra-começo?

Trawny: Sim, isso se torna uma questão porque os gregos não tinham Heidegger (risos)... Heidegger pensou, de certo modo, e isso está bastante claro nos Cadernos Pretos, que a filosofia deve ser um pensamento ontohistorial [seinsgeschichtliche Denken]. Ele não conectou esse projeto ao homem-Heidegger, pois ele pensava que toda filosofia deve ser um pensar historial. Em outros Cadernos, por exemplo, ele critica Husserl por este não haver compreendido o pensar historial sobre ser, mas Husserl nem ao menos conhecia isso! De volta à sua questão, a diferença é que Heidegger é um pensador da historicidade de Ser, enquanto que os gregos nunca tiveram um pensador nesses moldes. É como a perspectiva hegeliana (risos), ele era o único que realmente entendia o que estava acontecendo. Curiosamente, para ele, não é uma coincidência o que se passou na Alemanha, e somente um alemão poderia entender isso.

Soraya: Ele usa várias vezes, nesse primeiro volume, a expressão "somente poucos"15: somente poucos podem vislumbrar o que a filosofia - através dele - tenta alcançar. Você mais ou menos tratou dessa questão em seu livro Adyton ${ }^{16}$. Então, parece que filosofia não é para todo mundo. Acredito que até certo ponto possamos concordar com isso. Assim sendo, especialmente no que concerne o nosso tempo, épossivel filosofar

15. Cf.: HEIDEGGER, M. Überlegungen II-VI (Scbwarze Hefte 1931-1938), p. 277, $282,332,361$.

16. TRAWNY, Peter. Adyton: A filosofia esotérica de Heidegger. Trad. Marcia Calvalcante de Sá Schuback Rio de Janeiro: Mauad X, 2013. 
e ser politicamente correto? Quero dizer, sem cair na armadilha de pensar que se trata de algo especial, para "escolbidos", especiais?

Trawny: Isto que Heidegger tenta fazer com essa questão é, a meu ver, uma banalidade. Claro que há uma certa tradição em fazer uma diferença esotérica e exotérica, mas, como eu disse antes, não é muito inteligente afirmar isso. Em 2.700 anos de filosofia, poderíamos talvez falar de 50 filósofos? Não temos mais do que isso, na verdade... Não somente entre os gregos e alemães, mas incluindo Heráclito, Anaximandro, etc. Isto perfaz dois filósofos a cada século? Talvez.... Como Nietzsche algumas vezes disse, filósofos são animais raros, e todos sabem disso. No futuro, não vamos lidar com os textos de Peter Trawny, talvez lidemos com os de Alain Badiou, talvez...

Soraya: ...vamos desejar um futuro melhor para nossas crianças...

Trawny: Ser um filósofo quer dizer mais do que filosofar em determinadas situações. Eu diria que mesmo um homem comum pode se encontrar em situações nas quais filosofa, mas ele não é um filósofo. Então, ser um filósofo é algo muito especial a meu ver. Mas, então Heidegger faz disso algo grandioso, ele arruína a ideia ao dizer que "o domínio público não é capaz de compreender-me", não é capaz de compreender Platão, Nietzsche... Mas claro que o domínio público não é capaz de compreender Kant; é óbvio que o domínio público nunca está interessado em ler filosofia de modo intenso. Mas essa não é a questão relevante sobre o domínio púbico... E do modo como Heidegger pensa, quer dizer: as pessoas não têm Nietzsche como modelo do cotidiano; elas têm Pelé (risos), mas não Nietzsche, então, eu tenho que criar uma esfera esotérica em que eu posso falar para as pessoas que podem me compreender, e esses são poucos.... Bem, como eu disse, isso não é relevante a meu ver.

Soraya: Mas parece que isso evidencia e se soma à frustração crescente de Heidegger; estar entre os poucos e ter aparentemente tão pouco suporte de seus colegas, é como se todos à sua volta estivessem errados...

Trawny: Sim, exatamente isso!

Soraya: Um pouco delirante, mas também um pouco triste...

Trawny: Você acha?

Soraya: Sim. 
Trawny: Não se deve acreditar em cada aspecto do texto... Ele tem um ídolo, um modelo que ele tenta exercitar e esse modelo é claramente Nietzsche. E então o gesto nietzschiano está muito presente; o gesto de exclusividade, de solidão, que é o gesto de Zaratustra vivendo nas montanhas. Em certo sentido, é uma grande encenação. E eu acredito que Heidegger queria que fosse assim. Por exemplo, no final dos anos 40, ele continua com esse tom desesperado nos Cadernos. Ao mesmo tempo, ele escreve outro texto, chamado Os Quatro Cadernos ${ }^{17}$, e nesse ele tem um tom diferente! Não há nada desse ressentimento violento, é ao contrário uma filosofia simples e clara. Não devemos esquecer de que, nos Cadernos Pretos, Heidegger é alguém que sabe exatamente o que está fazendo...

Soraya: Então, tendo em vista o já foi mencionado no começo, não se trata de encenaç̧ão, mas premeditação...

Trawny: Isto está bastante claro, temos que ver essa influência nietzschiana no seu estilo. Não somente ele tenta escrever como Nietzsche, como ele exagera a perspectiva de Nietzsche. Ele tenta fazer Nietzsche mais Nietzsche do que ele jamais foi... Você vê que ele está todo o tempo falando do silêncio [Schweigen], que o domínio público é um buraco perdido, ninguém se importa, isto é obviamente de certo modo uma temática nietzschiana.

Soraya: Outro ponto neste volume que eu gostaria de abordar é o fato de Heidegger estar, a todo momento, jogando com opostos: visão de mundo x filosofia, digno de ser questionado [Fragwürdige] x questionável [Fragliche] ${ }^{18}$; ou o gigantesco [Riesige] $x$ o grande [Große], ou a tecnificação [Technisierung] x o pensar o sentido [Besinnung]. É mesmo assim? Não bá possibilidades, mas apenas ou tudo ou nada, ou a filosofia ou o perigo da mediocridade [Durchnittlicbkeit] ${ }^{19}$ ?

Trawny: É muito importante reconhecer que ele desempenha um certo maniqueísmo... Assim como na revolução, há o bem e o mal e nada de intermediário. Isso é muito forte e se torna mais e mais forte nos cadernos posteriores ainda nos anos 30 , nos quais ele chega a falar de

17. HEIDEGGER, M. Vier Heften, Vol. 99. Frankfurt: V. Klostermann. (não publicado).

18. HEIDEGGER, M. Überlegungen II-VI (Schwarze Hefte 1931-1938), p. 353

19. Idem, p. 330. 
uma purificação de ser para com os entes [Seienden]. Ele interpreta a diferença ontológica como uma diferença com a qual temos que lidar em termos de uma de-cisão, Ser ou entes. Tudo o que pertence ao domínio público, à ciência, à tecnologia, aos nazistas, aos judeus, tudo isso, trata-se de entes, e deve ser recusado. Tudo isso está do lado negativo. Isso é tão forte nesses manuscritos, que vem impregnado de ira. Como você mencionou, ele está muito revoltado contra os entes (risos). É óbvio que não se pode dizer o que é ser enquanto tal, e esse é um dos grandes problemas dessa filosofia: se você tentasse perguntar: Heidegger, então qual é sua alternativa para tudo isto, para a tecnologia, o que você realmente quer?

Soraya: Essa é a questão, pois aparentemente, assim como aconteceu com os gregos (no que diz respeito ao seu modo de encontrar os entes), não bá nada que possamos fazer a respeito...

Trawny: Talvez os gregos fossem uma espécie de imagem... Mas que imagem é essa? Bebemos vinho o dia inteiro, temos nossos amores, entre um amor e outro bebemos nosso vinho, lemos Hölderlin, talvez trabalhamos duas horas no campo (risos) e fazemos tudo de novo... Não digo que sou contra isso...

Soraya: Não, ninguém deveria ser contra isso, mas é de fato problemático...

Trawny: Sim, a vida seria boa assim (risos), mas isso não é um projeto filosófico. Você não pode levá-lo às pessoas... Agora, de volta ao assunto, esse é precisamente o problema quando Heidegger está criticando a ciência ocidental nos anos 1933-34. Ele tenta desenvolver sua própria alternativa. Você vê no texto que leu que há um novo tipo de saber ${ }^{20}$. Mas se você pensar responsavelmente, se você pudesse perguntar a ele por favor, conte-nos sobre esse tipo de saber além da ciência ocidental? Então é praticamente impossível dizer algo a respeito. Quando ele fala em abolir a ciência ocidental, é como a sua predileção por Hölderlin, é esquisito. Claro que ninguém deseja somente calcular na vida, isso não é algo belo ou interessante, mas como um filósofo, você deve poder ver o outro lado. Se estamos lidando com a tecnologia, a mídia, por um lado poderíamos dizer "dane-se a mídia", mas não se pode negar que de fato temos um papel nela, não faz sentido apenas dizer "dane-se a mídia". Essa é uma posição

20. Idem, p. 457. 
ridícula. Então, em seu maniqueísmo, Heidegger sustentou naquela época posições que são ridículas.

Soraya: Outra questão muito presente para mim em todo o volume 94 é a relação teoria versus práxis ${ }^{21}$. Nesse sentido, refiro-me à impossibilidade da filosofia de fazer algo a respeito e, ao mesmo tempo, à filosofia sendo a unica possibilidade. Talvez seja isso que você tenha formulado sobre a ideia de metapolítica [Metapolitik] ${ }^{22}$ presente nesses cadernos. O cerne dessa relação teoria versus práxis poderia ser uma maneira de nos aproximarmos do conceito de metapolítica para Heidegger? Eu realmente vejo essa relação presente em todo o volume...

Trawny: Claro que tem a ver com isso. Mas o que realmente importa é reconhecer que nessa época, 1933, ele realmente diz "parem a filosofia ${ }^{23}$, iniciem a metapolítica". Nessa situação revolucionária, ele diz que temos que romper com a filosofia. Veja, esse é um pensamento interessante, mas o que vem a ser então metapolítica? De certo modo, é a metafísica do povo historial, e isto é provavelmente o que ele está tratando nos Cadernos Pretos, o que ele pensa ser metapolítica.

Soraya: Mas não poderíamos considerar a metapolítica como algo, se não apolítico, ao menos pré-político? Estou aqui me referindo à leitura de Heidegger de Hölderlin no Volume $53^{24}$, no qual ele discute o sentido fundacional de polis, algo que você também já abordou filosoficamente ${ }^{25}$. Então, nessa perspectiva, seria a metapolítica algo realmente político?

Trawny: Claro que não é política como a conhecemos, não é também filosofia política como a conhecemos. É uma tentativa de romper com a filosofia política, mas não é o bastante para que nós adiramos à ideia. É uma tentativa, uma proposta que soa interessante, mas não se pode ir adiante com ela. Claro que não é mera práxis... Eu estudei pessoalmente a questão do terrorismo alemão e da teoria de esquerda por algum tempo. Como você sabe, no final dos anos 60 , Adorno era

21. Idem, p. $134,324$.

22. Idem, p. 115.

23. Idem, p. 226.

24. HEIDEGGER, M. Hölderlins Hymne "Der Ister". Hrsg. von Walter Biemel. Frankfurt: V. Klostermann, 1984.

25. TRAWNY, P. Sokrates oder die Geburt der Politischen Pbilosopbie. Würzburg: Königshausen \& Neumann, 2007. 
o filósofo que fazia teoria, e os estudantes alemães, de um modo radical, disseram "parem com a teoria, porque falar sobre a situação social é inútil, há de se pegar uma arma e matar os capitalistas", etc. Não se pode fazer uma revolução da sua escrivaninha, é preciso ir à prática, e é o que fizeram, eles se armaram e mataram pessoas ${ }^{26}$. Esse foi exatamente o tipo de decisão entre teoria e prática, mas com Heidegger não é o mesmo. Afinal, ele nunca sacou uma arma e matou professores de filosofia (risos)...

Soraya: Mas ele também compreendeu a diferença entre teoria e prática de outro modo, no exercício do dizer, ou a tentativa de pensar a cada vez o mesmo; ao mesmo tempo, isso pode ser muito prático, ou não?

Trawny: Não estou certo de que há um sentido prático, há um sentido para a vida, mas... como você sabe, Heidegger e também Wittgenstein nos dizem que a teoria é a verdadeira prática... Mas de um modo político, não faz sentido a meu ver. De um modo político, talvez, seja melhor pegar uma arma (risos). A revolução tem de ser feita. Essa é a fraqueza da filosofia, afinal. Mas sei o que significa, de volta ao texto, você tem razão em pensar metapolítica assim. Para dizer de outro modo, metapolítica é a tentativa de trazer o pensamento para esse mundo, de uma maneira que a filosofia não havia feito até então. Esse é o sacrifício da filosofia, parem com o negócio acadêmico, agora temos de sacrificar esse tipo de pensar e realizar um outro pensar, e esse pensar, como você mencionou antes, pertence a uma determinada situação, isso é verdade.

Soraya: Então, não se trataria de um reagir passivo filosoficamente, mas de uma filosofia performante?

Trawny: Sim, nas Contribuições ${ }^{27}$, Heidegger diz que a filosofia é saber maestral [herrschaftliches Wissen], e está bem claro que ele pensa a filosofia como a única maneira de organizar o mundo, de criar o mundo.

Soraya: Tudo nesse volume parece extremamente personificado, pessoal. Heidegger afirma que é preciso parar com a filosofia, mas talvez não seja preciso muita ajuda, a filosofia parece já estar caminhando para um fim, ou já tenba terminado talvez. E,

26. Facção do Exército Vermelho (RAF) ou Grupo Baader-Meinhof.

27. Heidegger, M. Beiträge zur Philosopbie (von Ereignis). Ed. F. V. Hermann. Frankfurt: V. Klostermann, 1989. 
então, chegamos ao boje, nós depois de Heidegger. Como um diálogo épossível, caso seja? Veja nós aqui, cientificamente discutindo cada palavra - porque nosso modo de ser é científico... Eu não me refiro somente à questão da impossibilidade de alcançar aquele instante filosófico [de Heidegger], mas da possibilidade em geral da filosofia boje: ainda podemos fazê-la?

Trawny: Não este tipo de performance filosófica acabou. Temos que encontrar uma nova sobriedade, não podemos mais ter aquele gesto. Contudo, eu penso que todos podem aprender com Heidegger, não somente com o filósofo - esse animal raro. Todo filósofo deve, de um certo modo, representar essa liberdade do pensar. A liberdade do pensar na qual se pode realmente alcançar e ter visões extremas, sem medo de assumir posições extremas, de estar fora do circuito principal. É claro que se deve estar ciente de que este não é o real sentido da filosofia, o de encontrar uma posição extrema, fora do grande circuito. Esse não é o sentido da filosofia, mas pertence às suas possibilidades, e um filósofo deve aceitar isso. Heidegger é, nesse sentido, o filósofo que representa tal possibilidade da maneira mais autêntica. Deve-se estar preparado para tudo no pensar. Isso pertence à liberdade da filosofia. É óbvio que isso não quer dizer que se tenha de ser antissemita, claro que não! Isso é loucura, mas deve-se ser livre o bastante para reconhecer a profundidade dessa sobriedade do pensar. Este é um pressuposto para a filosofia em todos os tempos e para a filosofia que virá. Este aspecto é representado por Heidegger da mais pura forma, e não por Gadamer, Habermas, ou Dennett... Heidegger demonstra isso nos Cadernos Pretos.

Soraya: Agora, por fim, falando um pouco sobre sua própria filosofia, eu poderia jurar que você escreveu Medium und Revolution ${ }^{28}$ sob influência de algumas das pistas, indícios [Winke] que Heidegger nos dá nos Cadernos...

Trawny: Não, aliás, eu não conhecia os Cadernos Pretos quando escrevi Medium und Revolution. Esse livro tem uma determinada estratégia de dificultar uma discussão clara, em um certo sentido...

Soraya: De fato, é um texto difícil... Nele, você também conjuga alguns opostos, mas me parece claro que você não pretende discutir revolução em uma perspectiva causal; mas discuti-la do mesmo modo como, por exemplo. Heidegger discute superação [Überwindung], ou seja, não como "uma jornada de um ponto A para B", como o

28. TRAWNY, P. Medium und Revolution. Berlim: Matthes und Seitz, 2010. 
passar de uma etapa a outra, linearmente. Assim, me parece mais que a sua revolução é uma figura, aliás bela, para discutir a temporalidade. Mesmo que esteja claro que sua discussão também se dá à luz dos acontecimentos de mundo na época (Primavera Árabe etc). A sua questão sobre o sentido de revolução seguirá adiante?

Trawny: Eu escrevi um manuscrito bem extenso sobre tecnologia, capital e meio ${ }^{29} \ldots$ Deve ser um tratado filosófico sobre a liberdade. Eu tentei lidar de modo sistemático com determinados problemas, uma nova ontologia sob a base da tecnologia, capital e meios, pois esta é a nossa tarefa do pensar hoje. Pensar quer dizer lidar com a tecnologia, economia e meios. Nesse sentido, se há algo que temos que abordar hoje é esse tipo de estrutura universal. Mas eu descobri que não poderia dar esse manuscrito para alguém ler (risos)...

Soraya: E por que não?

Trawny: O projeto é muito complicado. Eu tento dizer que a conexão entre tecnologia, economia e meios de massa é matemática... Pois de fato não temos outra alternativa além de ver que tudo nessa estrutura pode ser formalizado na matemática. Para mim, isso tem a ver com Spinoza, com seu problema da causalidade e da perda de liberdade... Mas eu descobri que é impossível dizer isso desse modo. É de certo modo ridículo (risos)... Então, de fato, eu não escreverei mais de um modo sistemático, mas trabalharei em algo que vai se chamar Medium und Revolution II. Estou começando a escrever... ${ }^{30}$

Soraya: Muito obrigada, professor.

Recebido em 15.04.2014

Aceito em 12.10.2014

29. TRAWNY, P. Tecbnik. Kapital.Medium. Das Universale und die Freiheit. Berlim: Matthes und Seitz, no prelo.

30. De fato, conforme indicado na nota anterior, posteriormente à essa entrevista, o autor reviu sua decisão e lançará ainda esse ano o livro como originalmente intitulado "Técnica, Capital, Meio. O Universal e a Liberdade". 